\title{
Analysis of the Complete Genome Sequence of Bacillus atrophaeus GQJK17 Reveals Its Biocontrol Characteristics as a Plant Growth-Promoting Rhizobacterium
}

\author{
Jinjin Ma, Chengqiang Wang $\mathbb{D}$, Haide Wang, Kai Liu, Tongrui Zhang, Liangtong Yao, \\ Zhou Zhao, Binghai Du $\mathbb{D}$, and Yanqin Ding $\mathbb{D}$
}

College of Life Sciences, National Engineering Laboratory for Efficient Utilization of Soil and Fertilizer Resources, Shandong Key Laboratory of Agricultural Microbiology, Shandong Agricultural University, Taian, China

Correspondence should be addressed to Binghai Du; du_binghai@163.com and Yanqin Ding; dyq@sdau.edu.cn

Jinjin Ma and Chengqiang Wang contributed equally to this work.

Received 6 February 2018; Revised 14 May 2018; Accepted 21 May 2018; Published 26 June 2018

Academic Editor: Pengjun Shi

Copyright (C) 2018 Jinjin Ma et al. This is an open access article distributed under the Creative Commons Attribution License, which permits unrestricted use, distribution, and reproduction in any medium, provided the original work is properly cited.

Bacillus atrophaeus GQJK17 was isolated from the rhizosphere of Lycium barbarum L. in China, which was shown to be a plant growth-promoting rhizobacterium as a new biological agent against pathogenic fungi and gram-positive bacteria. We present its biological characteristics and complete genome sequence, which contains a 4,325,818 bp circular chromosome with 4,181 coding DNA sequences and a $\mathrm{G}+\mathrm{C}$ content of $43.3 \%$. A genome analysis revealed a total of 8 candidate gene clusters for producing antimicrobial secondary metabolites, including surfactin, bacillaene, fengycin, and bacillibactin. Some other antimicrobial and plant growth-promoting genes were also discovered. Our results provide insights into the genetic and biological basis of $B$. atrophaeus strains as a biocontrol agent for application in agriculture.

\section{Introduction}

In recent years, the yield and quality of many medicinal plants, vegetables, fruits, and crops have decreased because of plant diseases caused by soil-borne pathogens [1-4]. Moreover, a large number of chemical pesticides and fertilizers have been used in agriculture that further caused quality reduction of agricultural products [5], pathogen resistance to chemicals [1], and environmental pollution [6]. Plant growthpromoting rhizobacteria (PGPR) are a group of strains that localize in the plant rhizosphere and play an important role in preventing and controlling soil-borne diseases [7], promoting plant growth and development $[8,9]$, enhancing stress tolerance [10], and regulating and improving the rhizosphere soil environment [11-13]. Bacillus species are an important group of PGPR, and some of them have been widely used in agriculture as biocontrol agents [14-16].

Bacillus atrophaeus as a group of useful bacterium has been studied in many aspects. $B$. atrophaeus was verified to be a known biomolecule producer [17], which could produce bacteriocin [18], bioactive compounds [19], and biosurfactant proteins [20]. B. atrophaeus is also an important group of PGPR. B. atrophaeus M-35 was recognized as a PGPR member, and it was previously identified to effectively inhibit potato dry rot and rhizome rot of ginger caused by Fusarium species [21,22]. B. atrophaeus also exhibits a strong inhibitory effect against poplar anthracnose caused by a predominant fungus, Colletotrichum gloeosporioides [23]. B. atrophaeus CAB-1 was reported to display a high inhibitory activity against various fungal pathogens and was capable of suppressing cucumber powdery mildew and tomato gray mold [24]. Moreover, B. atrophaeus had an extraordinary activity in root colonization and crop protection [25], and it was verified to promote the growth of Zea mays $L$. and Solanum lycopersicum [26]. However, the biocontrol mechanisms of $B$. atrophaeus species as PGPR have not been well characterized to date. 
The goji berries produced by Lycium barbarum L. have nutritional health and medicinal value $[27,28]$ because of the contained components, such as Lycium barbarum L. polysaccharides and betaine [29, 30]. They can enhance human immunity, regulate blood fat, lower blood pressure, inhibit the growth and mutation of cancer cells, resist radiation, and so on [31-33]. So, the cultivated land for Lycium barbarum L. has been increased year by year, especially in China. With the continuous expansion of planting areas for Lycium barbarum L. and the continuous planting activity year by year, a variety of fungal soil-borne diseases are arising and seriously affecting the yield and quality of Lycium barbarum L. Root rot is one of the most important diseases of Lycium barbarum L. and Fusarium spp. (e.g., F. solani) are the main pathogens [34].

Strain GQJK17 was isolated from the rhizosphere of Lycium barbarum L. in Ningxia, China, and identified to be a plant growth-promoting rhizobacterium aimed at the root rot of Lycium barbarum L. It was identified to be $B$. atrophaeus and has the most significant inhibition effect on the root rot pathogen $F$. solani among all the selected strains. To further study the genetic basis and molecular mechanism of its biocontrol ability, we performed the complete genome sequencing and annotation. The secondary metabolic gene clusters for pathogen resistance and some plant growthpromoting genes are discovered.

\section{Materials and Methods}

2.1. Strain Isolation and Property Analysis. Strain GQJK17 was isolated from rhizosphere soil samples of Lycium barbarum L. collected from Ningxia, China. All physiological and biochemical tests were performed at $37^{\circ} \mathrm{C}$. The colony morphology was determined after $24 \mathrm{~h}$ incubation on LB agar medium. Cellular morphology and spore detection were performed by spore staining using $5 \%$ malachite green dye and $0.5 \%$ fuchsin dye [43] and examined by fluorescence microscopy (Olympus, Japan). Some physiological and biochemical characteristics of GQJK17 were determined as follows. Oxidase activity was determined using 1\% solution of tetramethyl- $p$-phenylenediamine [44]. Catalase activity was determined by assessing the production of bubbles after the addition of a drop of $3 \% \mathrm{H}_{2} \mathrm{O}_{2}$ [45]. Nitrate reduction, methyl red test (M-R), Voges-Prokauer reaction (V-P), indole production, and carbon utilization were tested using the bacteria microbiochemical identification tube (HOPEBIO, China) [45].

2.2. The Phylogenetic Analysis. The genomic DNA of strain GQJK17 was extracted using the genomic DNA kit (TIANGEN, China). The polymerase chain reaction (PCR) was performed as follows: $5 \mathrm{~min}$ at $95^{\circ} \mathrm{C}$ (predegeneration); 30 cycles of $1 \mathrm{~min}$ at $94^{\circ} \mathrm{C}$ (denaturation), $1 \mathrm{~min}$ at $56^{\circ} \mathrm{C}$ (annealing), and $1 \mathrm{~min}$ at $72^{\circ} \mathrm{C}$ (extension); followed by $10 \mathrm{~min}$ at $72^{\circ} \mathrm{C}$ (final extension). The $16 \mathrm{~S}$ rDNA sequence was obtained using primers 27F ( $5^{\prime}$-AGAGTTTGATCCTGGCTCAG-3) and 1492R ( $5^{\prime}-$ GGTTACCTTGTTACGACTT- $\left.3^{\prime}\right)$ and then analyzed by the National Center for Biotechnology Information (NCBI) (http://www.ncbi.nlm.nih.gov). The neighborjoining phylogenetic tree was constructed with some species of the genus Bacillus based on the $16 \mathrm{~S}$ rDNA sequences by MEGA 6.0.

2.3. The Determination of Antagonistic Properties. The antagonistic experiments were performed as reported [46]. The antifungal activity of strain GQJK17 was tested against Fusarium solani. F. solani with a diameter of $6 \mathrm{~mm}$ was inoculated in the center of a PDA agar plate and cultured at $28^{\circ} \mathrm{C}$ for one day. Then, strain GQJK17 was inoculated in one side of $F$. solani at a distance of $2 \mathrm{~cm}$ and incubated for another 3 to 5 days. After incubation, the inhibition zone was observed. The antibacterial assays of GQJK17 were performed against Escherichia coli DH5 $\alpha$ and Bacillus subtilis 168. The precultured strain $\mathrm{DH} 5 \alpha$ or 168 was incubated in $5 \mathrm{~mL}$ of $\mathrm{LB}$ liquid medium at $37^{\circ} \mathrm{C}$ for $10 \mathrm{~h}$. Then, $1 \mathrm{~mL}$ of the culture was mixed with $100 \mathrm{~mL}$ of LB semisolid medium (with $1 \%$ agar) and poured into a sterile Petri dish. Strain GQJK17 was inoculated on the center of a cooled medium and incubated at $28^{\circ} \mathrm{C}$ for $24 \mathrm{~h}$.

2.4. Medium Optimization. The culture medium of strain GQJK17 was optimized using bean sprouts as the basic medium. The plate counting method was used to estimate the strain growth. The suitable carbon sources (sucrose, glucose, lactose, corn flour, and soluble starch), nitrogen sources (including the organic nitrogen sources: beef extract, peptone, yeast powder, and soybean meal, and the inorganic nitrogen source: $\left(\mathrm{NH}_{4}\right)_{2} \mathrm{SO}_{4}, \mathrm{NH}_{4} \mathrm{NO}_{3}, \mathrm{NH}_{4} \mathrm{Cl}$, and Urea), and inorganic salts $\left(\mathrm{MgSO}_{4}, \mathrm{CaCO}_{3}, \mathrm{~K}_{2} \mathrm{HPO}_{4}\right.$, and $\left.\mathrm{KH}_{2} \mathrm{PO}_{4}\right)$ were determined by single factor experiments. The orthogonal test (designed by orthogonal design assistant II V3.1) [47] was used to predict the optimum medium for strain GQJK17.

2.5. Genome Sequencing and Annotation. The complete genome of strain GQJK17 was sequenced by the Illumina HiSeq and PacBio platforms. The SMRT Analysis 2.3.0 [48] (https:/github.com/PacificBiosciences/SMRT-Analysis/wiki/ SMRT-Pipe-Reference-Guide-v2.3.0) was used to assemble the whole genome sequence. The NCBI Prokaryotic Genomes Automatic Annotation Pipeline (PGAAP) was used to perform the gene annotation. The gene functions were further analyzed by BLASTP using five databases (Cluster of Orthologous Groups of proteins: COG, Gene Ontology: GO, Kyoto Encyclopedia of Genes and Genomes: KEGG, Non-Redundant Protein Database: NR, and Swiss-Prot). The carbohydrate-active enzyme analyses of the genome also utilized the Carbohydrate-Active enZYmes Database (CAZy) v.20161020 [49] (http://www.cazy.org/). RepeatMasker (3-3-0, http://www.repeatmasker.org/) was used to predict interspersed repeated sequences, and TRF (4.04, http://tandem.bu .edu/trf/trf.html) was used to search tandem repeats. tRNAscan-SE 1.3.1, rRNAmmer 1.2, and Rfam were used to determine tRNA, rRNA, and sRNA, respectively. The potential secondary metabolic gene clusters were predicted using antiSMASH v.4.0.2 [50]. IslandViewer 4 (http://www .pathogenomics.sfu.ca/islandviewer2/query.php) was used to 


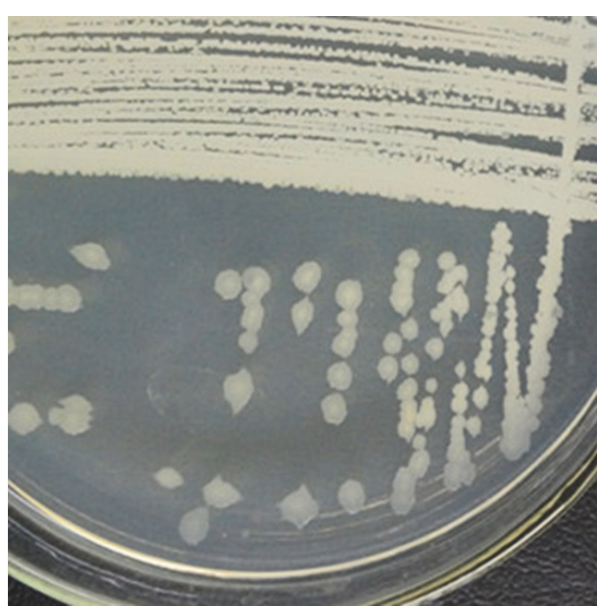

(a)

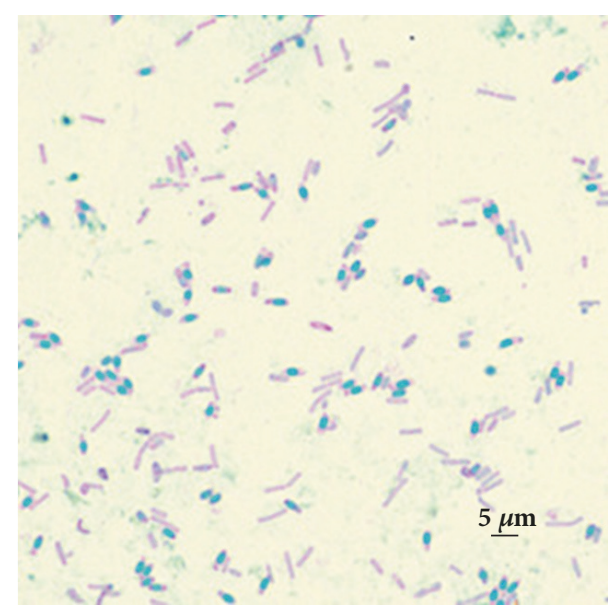

(b)

FIGURE 1: Morphological characteristics of GQJK17. Colony morphology (24 h) (a) and cellular morphology and spore (magnification $10 \times$ 100 ) (b). GQJK17 was inoculated on LB agar medium and incubated at $37^{\circ} \mathrm{C}$ for $24 \mathrm{~h}$. Spores were stained with $5 \%$ malachite green dye and $0.5 \%$ magenta dye.

predict genomic islands (GIs) [51]. The complete and circular genome map was created by Circos v.0.64 [52] (http://www .circos.ca/), including noncoding RNAs and gene function annotations.

\section{Results}

3.1. The Isolation and Identification of Strain GQJK17. Strain GQJK17 was isolated from the rhizosphere soil of Lycium barbarum L. in Ningxia, China, and cultivated on LB medium at $37^{\circ} \mathrm{C}$. The colony morphology of strain GQJK17 is nearly circular, smooth, moist, and milky white after being cultured on LB agar medium for $24 \mathrm{~h}$. The cellular morphology of strain GQJK17 is rod-shaped and strain GQJK17 can produce spores. Its colony and cellular morphology are shown in Figures 1(a) and 1(b). Some physiological and biochemical traits of strain GQJK17 were tested. The properties of oxidase activity, starch hydrolysis, M-R, and indole production are negative, but the catalase activity, citrate utilization, nitrate reduction, and V-P are positive. The carbon utilization experiments showed that strain GQJK17 could utilize mannitol, Arabic candy, sorbitol, and maltose, but not xylose, cellobiose, and lactose (Table 1).

The phylogenetic analysis of strain GQJK17 based on $16 \mathrm{~S}$ rDNA sequences was conducted by MEGA 6.0 with related Bacillus species (Figure 2) to show the phylogenetic relationships. Strain GQJK17 was successfully clustered to $B$. atrophaeus. Up to now, only four complete genome sequences of this species have been obtained except GQJK17, including strains SRCM101359, 1942, NRS 1221A, and BA59. The closest relative of strain GQJK17 is B. atrophaeus SRCM 101359.

3.2. The Biocontrol Efficacy of Strain GQJK17. The antagonistic activities of strain GQJK17 against F. solani, B. subtilis 168, and E. coli DH5 $\alpha$ were tested. In Figure 3, it is shown that strain GQJK17 exhibits antagonistic activity against $F$. solani
TABLE 1: Characteristics of physiology and biochemistry of GQJK17.

\begin{tabular}{lccc}
\hline Properties & GQJK17 & Properties & GQJK17 \\
\hline Oxidase & - & Mannitol utilization & + \\
Catalase & + & Xylose utilization & - \\
Citrate utilization & + & Cellobiose utilization & - \\
Starch hydrolysis & + & Arabic candy utilization & + \\
Nitrate reduction & + & Sorbitol utilization & + \\
methyl red (M-R) & - & Maltose utilization & + \\
Voges-Prokauer (V-P) & + & Lactose utilization & - \\
Indole production & - & & \\
\hline
\end{tabular}

and B. subtilis but no effect on E. coli indicating potential applications for controlling some pathogenic fungi and grampositive bacteria. Among all the isolated Bacillus strains, GQJK17 has the most significant inhibitory effect on the root rot pathogen F. solani of Lycium barbarum L. GQJK17 can adapt to the saline-alkali environment in the isolated area Ningxia. As a PGPR, strain GQJK17 could also produce siderophores and show casein degradation activity (data not show). Thus, GQJK17 was a potential strain to improve plant growth as a biocontrol agent or microbial fertilizer.

3.3. The Medium Optimization of Strain GQJK17. To adapt the actual application of strain GQJK17, we also optimized the culture medium of strain GQJK17. The bean sprouts were used as the basic medium, which could provide the necessary nutrients for strain GQJK17 growth and reduce production costs. By single factor experiments, the optimal sources of carbon, organic nitrogen, inorganic nitrogen, and inorganic salt of strain GQJK17 were determined to be glucose, soybean meal, $\mathrm{NH}_{4} \mathrm{NO}_{3}$, and $\mathrm{MgSO}_{4}$, respectively. The orthogonal experiments were designed (Supplementary S1) and the optimal medium contained 3\% glucose, $1.5 \%$ 


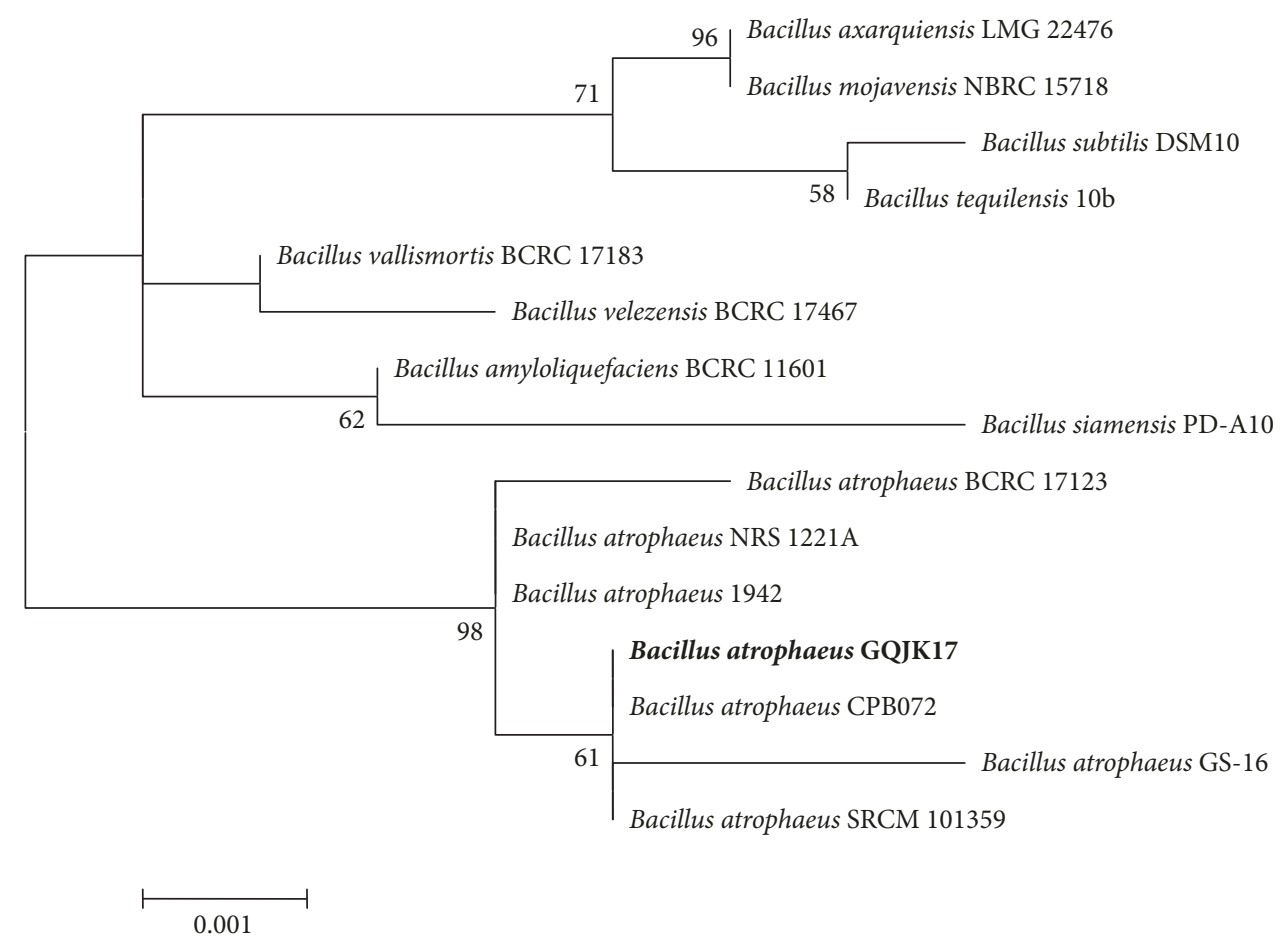

FIGURE 2: Neighbor-joining phylogenetic tree of B. atrophaeus GQJK17 and members of the genus Bacillus based on 16S rDNA gene sequences. The phylogenetic tree was constructed using the MEGA 6.0 program and evolutionary distances were computed by the Maximum Likelihood method. Bootstrap values (expressed as percentages of 1000 replications) $>50 \%$ are indicated at the branch points. The scale bar indicates 0.001 nucleotide substitutions per site.

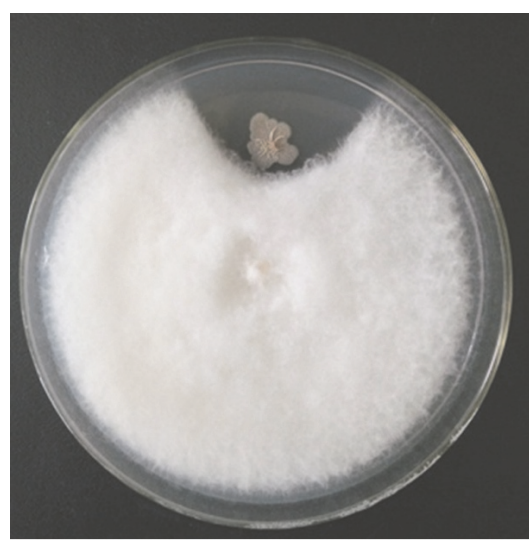

(a)

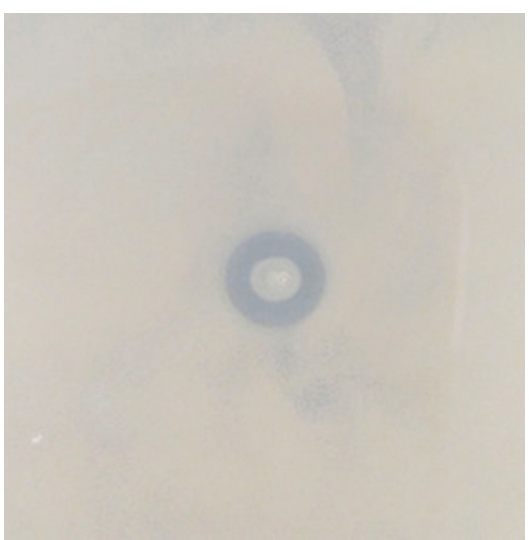

(b)

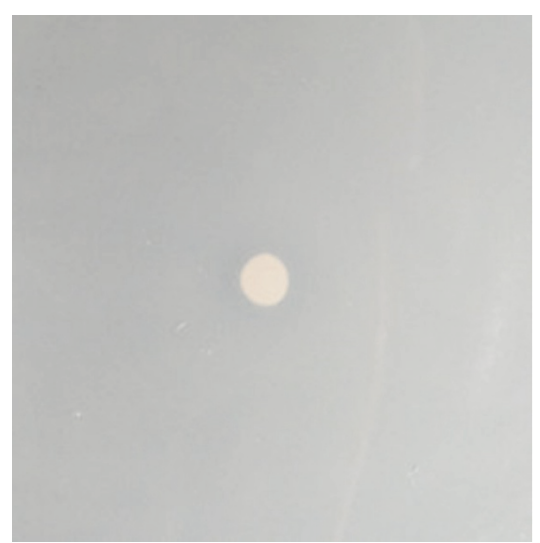

(c)

FIGURE 3: In vitro antagonistic activities of B. atrophaeus GQJK17 against F. solani (a), B. subtilis (b), and E. coli (c). The antifungal activity of GQJK17 was tested against $F$. solani. Newly cultivated hyphal plugs of $F$. solani were placed on the center of a PDA plate and incubated for 1 day at $28^{\circ} \mathrm{C}$. Then, strain GQJK17 was inoculated onto one side of the plug at a distance of $2 \mathrm{~cm}$ and incubated for another 3 days. The antibacterial assays of GQJK17 were performed against E. coli and B. subtilis. The precultured E. coli or B. subtilis was incubated in $5 \mathrm{~mL}$ of $\mathrm{LB}$ liquid medium for $10 \mathrm{~h}$ at $37^{\circ} \mathrm{C}$. Then, $1 \mathrm{~mL}$ of the culture was mixed with $100 \mathrm{~mL}$ of LB semisolid medium. Strain GQJK17 was inoculated on the center of the plate and incubated for 1 day at $28^{\circ} \mathrm{C}$.

soybean meal, $0.3 \% \mathrm{NH}_{4} \mathrm{NO}_{3}$, and $0.3 \% \mathrm{MgSO}_{4}$. The colony numbers of strain GQJK17 were significantly increased from $3.21 \times 10^{8} \mathrm{cfu} / \mathrm{mL}$ to $7.98 \times 10^{9} \mathrm{cfu} / \mathrm{mL}$ using the optimized medium.
3.4. Genome Sequence and Genome Features of Strain GQJK17. A total of $1,364 \mathrm{Mb}$ clean raw data were generated and the coverage of the genome was $307.9 \times$. From the 126,058 subreads, approximately $1,289,931,176 \mathrm{bp}$ were obtained. The 


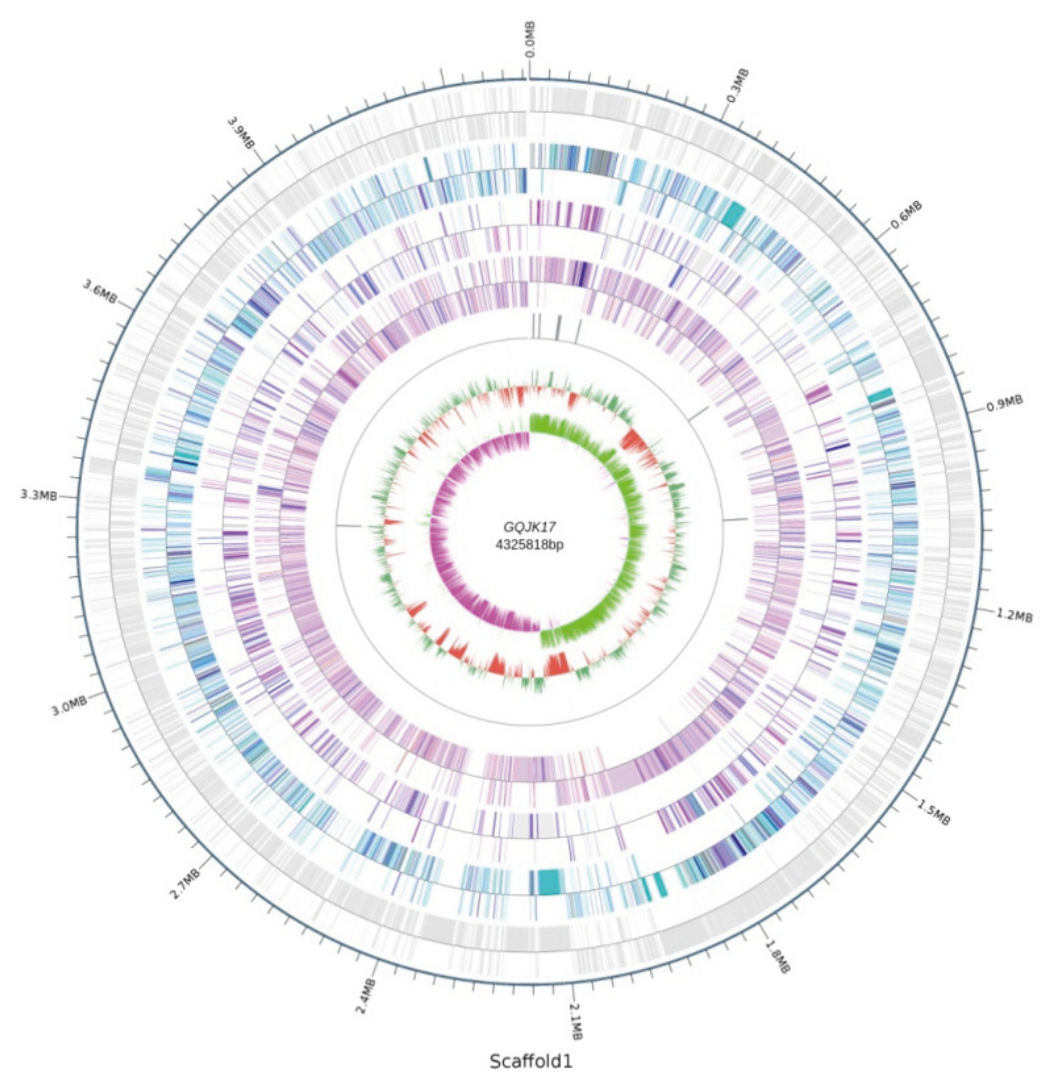

16s_rRNA
23s_rRNA
5s_rRNA
$\square$ sRNA
$\square$ tRNA

INFORMATION STORAGE AND PROCESSING

$\mathrm{J}$ : Translation, ribosomal structure and biogenesis

K: Transcription

L: Replication, recombination and repair

B. Chromatin structure and dynamics

CELLULAR PROCESSES AND SIGNALING

D: Cell cycle control, cell division, chromosome partitioning

$v$ : Defense mechanisms

T. Signal transduction mechanisms

M: Cell wall/membrane/envelope biogenesis

$\mathrm{N}$ : Cell motility

U: Intracellular trafficking, secretion, and vesicular transport

O: Posttranslational modification, protein turnover, chaperones

METABOLISM

C: Energy production and conversion

G: Carbohydrate transport and metabolism

E: Amino acid transport and metabolism

F: Nucleotide transport and metabolism

$\mathrm{H}$ : Coenzyme transport and metabolism

I: Lipid transport and metabolism

$\mathrm{P}$ : Inorganic ion transport and metabolism

Q: Secondary metabolites biosynthesis, transport and catabolism

POORLY CHARACTERIZED

$R$ : General function prediction only

$\mathrm{S}$ : Function unknown

Figure 4: Circular genome map of $B$. atrophaeus GQJK17. From the outside to the center, circle 1: the size of complete genome; circles 2 to 4: the predicted protein-coding genes by using COG, KEGG, and GO databases, respectively, different colors represent different function classifications; circle 5: ncRNA; circle 6: $\mathrm{G}+\mathrm{C}$ content, with $>43.26 \% \mathrm{G}+\mathrm{C}$ in green, with $\leq 43.26 \% \mathrm{G}+\mathrm{C}$ in red; the inner circle: $\mathrm{G}+\mathrm{C}$ skew, with $\mathrm{G} \%>\mathrm{C} \%$ in peak green, with $\mathrm{G} \%<\mathrm{C} \%$ in purple.

TABLE 2: The general genome feature of B. atrophaeus GQJK17.

\begin{tabular}{lc}
\hline Feature & Value \\
\hline Genome size (bp) & $4,325,818$ \\
G+C content (\%) & 43.3 \\
Total number of genes & 4,294 \\
Total size of protein-coding genes (bp) & $3,829,380$ \\
Protein-coding genes & 4015 \\
Average CDS size (bp) & 916 \\
rRNA number & 24 \\
tRNA number & 84 \\
ncRNA number & 5 \\
Pseudo genes (total) & 166 \\
\hline
\end{tabular}

genome of $B$. atrophaeus GQJK17 contains a 4,325,818 bp circular chromosome with a $\mathrm{G}+\mathrm{C}$ content of $43.3 \%$, including 4,015 protein-coding genes, 84 tRNA, 24 rRNA, and 5 ncRNA (Table 2 and Figure 4). No plasmid was found. The whole genome sequence of strain GQJK17 has been deposited in GenBank under the accession number CP022653. There were 3,373 genes that were assigned to the COG databases, accounting for $84.01 \%$ among the protein-coding genes (Table 3). Most genes have been annotated; however, $22.53 \%$ of the protein-coding genes are poorly characterized and are assigned to the $\mathrm{R}$ and $\mathrm{S}$ groups. The genes encoding amino acid transport and metabolism, transcription, carbohydrate transport and metabolism, and inorganic ion transport and metabolism account for a large proportion (each more than $6 \%)$. Furthermore, the analysis of CAZy showed that 154 genes were related to carbohydrate enzymes. This indicates the better absorption capacity and response ability of this species for amino acids, carbohydrates, and irons in the living environment.

3.5. Genetic Basis for Producing Antimicrobial and Plant Growth-Promoting Metabolites. Strain GQJK17 was selected due to its inhibition effects on pathogenic fungi and grampositive bacteria (Figure 3), which indicated the existence of antimicrobial gene clusters. In the genome of strain GQJK17, a total of 13 secondary metabolic gene clusters were predicted using antiSMASH (v.4.0.2) (Table 4), among them eight gene clusters belonging to nonribosomal peptide synthetases (NRPS) or polyketide synthetases (PKS). These clusters were mainly responsible for biological resistance. The potentially antifungal secondary metabolites were surfactin, fengycin, pelgipeptin, xenocoumacin, bacillomycin, and rhizocticin. Surfactin and pelgipeptin also have antibacterial abilities. There were also gene clusters for antibacterial effects only and 
TABLE 3: COG categories of B. atrophaeus GQJK17.

\begin{tabular}{|c|c|c|c|}
\hline COG code & Description & Number & Proportion \\
\hline B & Chromatin structure and dynamics & 1 & $0.03 \%$ \\
\hline $\mathrm{C}$ & Energy production and conversion & 179 & $5.31 \%$ \\
\hline $\mathrm{D}$ & Cell cycle control, cell division, chromosome partitioning & 35 & $1.04 \%$ \\
\hline $\mathrm{E}$ & Amino acid transport and metabolism & 340 & $10.08 \%$ \\
\hline $\mathrm{F}$ & Nucleotide transport and metabolism & 78 & $2.31 \%$ \\
\hline G & Carbohydrate transport and metabolism & 260 & $7.71 \%$ \\
\hline $\mathrm{H}$ & Coenzyme transport and metabolism & 126 & $3.74 \%$ \\
\hline I & Lipid transport and metabolism & 112 & $3.32 \%$ \\
\hline $\mathrm{J}$ & Translation, ribosomal structure and biogenesis & 162 & $4.80 \%$ \\
\hline $\mathrm{K}$ & Transcription & 289 & $8.57 \%$ \\
\hline $\mathrm{L}$ & Replication, recombination and repair & 120 & $3.56 \%$ \\
\hline M & Cell wall/membrane/envelope biogenesis & 186 & $5.51 \%$ \\
\hline $\mathrm{N}$ & Cell motility & 60 & $1.78 \%$ \\
\hline $\mathrm{O}$ & Posttranslational modification, protein turnover, chaperones & 101 & $2.99 \%$ \\
\hline $\mathrm{P}$ & Inorganic ion transport and metabolism & 217 & $6.43 \%$ \\
\hline Q & Secondary metabolites biosynthesis, transport and catabolism & 92 & $2.73 \%$ \\
\hline $\mathrm{R}$ & General function prediction only & 454 & $13.46 \%$ \\
\hline S & Function unknown & 308 & $9.13 \%$ \\
\hline $\mathrm{T}$ & Signal transduction mechanisms & 146 & $4.33 \%$ \\
\hline $\mathrm{U}$ & Intracellular trafficking, secretion, and vesicular transport & 45 & $1.33 \%$ \\
\hline $\mathrm{V}$ & Defense mechanisms & 62 & $1.84 \%$ \\
\hline
\end{tabular}

the predicted metabolites were bacillaene and anthracimycin. Compared with the other four complete genome sequences of this species, SRCM101359, 1942, NRS 1221A, and BA59, the main gene clusters predicted by antiSMASH (v.4.0.2) for producing antimicrobial secondary metabolites were generally similar. They all contained the biosynthetic gene clusters for surfactin, bacillaene, fengycin, rhizocticin, and bacillomycin. However, the biosynthetic genes of xenocoumacin were only discovered in strains GQJK17 and SRCM101359. In addition, the biosynthetic genes coding for pelgipeptin and anthracimycin only appeared in strain GQJK17. Our findings highlight the evolutionary conservation of molecular genetic mechanism of $B$. atrophaeus strains for biocontrol ability and the specialization of strain GQJK17.

There were four other secondary metabolic gene clusters in strain GQJK17 and the functions of those are still unclear. Interestingly, two gene clusters potentially producing terpenes were identified. Terpenes are a large class of organic compounds produced by some plants, bacteria, and fungi, which may be used as additives in food and cosmetics industries or exhibit antimicrobial or anticarcinogenic properties [53]. Some other antimicrobial-related genes could also be discovered in strain GQJK17, such as the synthetic genes of glucanase, ribonuclease, and proteases.

Moreover, the genome of strain GQJK17 contains many plant growth-promoting genes. One secondary metabolic gene cluster was predicted to produce bacillibactin, which is a kind of strong siderophore that can increase the absorption of ferric ions in soil for plant growth [54]. In addition to the synthetic gene cluster of bacillibactin, strain GQJK17 also harbors other plant growth-promoting genes codifying the production of useful substances, including butanone, phytase, and phosphatase. Other genes are likely involved in cell motility, molecular communication, and environmental responses.

3.6. Genomic Islands Analysis. The whole genome sequence of GQJK17 was analyzed by IslandViewer 4, and 14 GIs were discovered (Supplementary S2). Genomic Islands (GIs) are part of the genome sequences presenting the horizontal gene transfer from other species. The GIs in the genome of strain GQJK17 express a variety of proteins mainly involved in glycoside hydrolase, phage proteins, fimbrial proteins, transporters, and regulatory factors. Five phage protein genes are found in GIs, which indicate the previous infection by phages. A polyketide synthase, two glycoside hydrolases were identified, which are related to the antimicrobial activities of GQJK17. Some transcriptional regulators (e.g., LysR family regulator) can regulate the expression genes involved in metabolism, virulence, quorum sensing, and motility [55], and they might be related to the antagonistic properties. Type IV secretion protein Rhs can regulate cell-to-cell contactdependent competition [56]. Certain Rhs were also reported to have antibacterial activity.

\section{Discussion}

Lycium barbarum L. is a significant and commercial crop because of its nutritional and medicinal value [27]. In recent years, due to long-term cultivation and continuous cropping, 
TABLE 4: The potential gene clusters encoding the secondary metabolites in B. atrophaeus GQJK17.

\begin{tabular}{|c|c|c|c|c|c|}
\hline Number & Cluster Category $^{\mathrm{a}}$ & Metabolite $^{\mathrm{b}}$ & Position & Function & Reference \\
\hline 1 & Nrps & Surfactin & $\begin{array}{l}\text { BaGK_01865- } \\
\text { BaGK_02085 }\end{array}$ & $\begin{array}{l}\text { Antifungal, } \\
\text { Antibacterial }\end{array}$ & {$[15]$} \\
\hline 2 & $\begin{array}{c}\text { Bacteriocin-Nrps- } \\
\text { Transatpks- } \\
\text { Otherks }\end{array}$ & Bacillaene & $\begin{array}{l}\text { BaGK_09425- } \\
\text { BaGK_09810 }\end{array}$ & Antibacterial & {$[35]$} \\
\hline 3 & Transatpks-Nrps & Fengycin & $\begin{array}{l}\text { BaGK_10375- } \\
\text { BaGK_10710 }\end{array}$ & Antifungal & {$[15]$} \\
\hline 4 & $\begin{array}{c}\text { Ladderane- } \\
\text { Cf_fatty_acid -Nrps }\end{array}$ & Pelgipeptin & $\begin{array}{l}\text { BaGK_12700- } \\
\text { BaGK_12950 }\end{array}$ & $\begin{array}{l}\text { Antibacterial, } \\
\text { antifungal }\end{array}$ & {$[36]$} \\
\hline 5 & Transatpks & Anthracimycin & $\begin{array}{c}\text { BaGK_11000- } \\
\text { BaGK_11250 }\end{array}$ & Antibacterial & {$[37]$} \\
\hline 6 & Nrps-T1pks & Xenocoumacin & $\begin{array}{l}\text { BaGK_03970- } \\
\text { BaGK_04195 }\end{array}$ & Antifungal & {$[38]$} \\
\hline 7 & Cf_putative & Bacillomycin & $\begin{array}{c}\text { BaGK_20300- } \\
\text { BaGK_20325 }\end{array}$ & Antifungal & {$[39,40]$} \\
\hline 8 & $\begin{array}{c}\text { Sactipeptide- } \\
\text { Head_to_tail-Nrps }\end{array}$ & Rhizocticin & $\begin{array}{l}\text { BaGK_01040- } \\
\text { BaGK_01305 }\end{array}$ & Antifungal & [41] \\
\hline 9 & Nrps & Bacillibactin & $\begin{array}{l}\text { BaGK_16720- } \\
\text { BaGK_16940 }\end{array}$ & Siderophore & {$[42]$} \\
\hline 10 & Terpene & Unknown & $\begin{array}{c}\text { BaGK_06190 } \\
\text {-BaGK_0629 } \\
5\end{array}$ & & \\
\hline 11 & Terpene & Unknown & $\begin{array}{l}\text { BaGK_10750 } \\
\text {-BaGK_1084 } \\
5\end{array}$ & & \\
\hline 12 & T3pks & Unknown & $\begin{array}{c}\text { BaGK_11290 } \\
\text {-BaGK_1152 } \\
5\end{array}$ & & \\
\hline 13 & Thiopeptide & Unknown & $\begin{array}{l}\text { BaGK_17030 } \\
\text {-BaGK_1716 } \\
5\end{array}$ & & \\
\hline
\end{tabular}

${ }^{a}$ Cluster categories were analyzed by antiSMASH (v.4.0.2).

${ }^{\mathrm{b}}$ The secondary metabolites were predicted according to the gene clusters.

Lycium barbarum L. was increasingly affected by soil-borne diseases in China. Especially, the spread of root rot seriously affected the yield and quality of Lycium barbarum L. In this study, we screened out a strain GQJK17 from the rhizosphere of Lycium barbarum L. Biocontrol experiments showed that strain GQJK17 could inhibit the pathogen F. solani of Lycium barbarum L. root rot and also repress the growth of B. subtilis 168. Morphological observation and phylogenetic analysis showed that GQJK17 was closely related to B. atrophaeus CPB072. B. atrophaeus species is a PGPR which has considerable effects on inhibiting some soil-borne diseases and promoting the growth of some plants [22]. The biocontrol characteristics of strain GQJK17 revealed its important roles as a plant growth-promoting rhizobacterium. This strain provides an excellent resource for developing new microbial fertilizers and shows interesting prospects for agricultural applications.

To further study the genetic basis and molecular mechanism of strain GQJK17 as PGPR, we sequenced its complete genome that presented the genetic basis of its biocontrol function and a molecular background for subsequent transformation. Eight secondary metabolic gene clusters were found out, which might be responsible for its function as a new biocontrol agent. Some other plant growth-promoting genes for producing many useful substances were also found in strain GQJK17. Comparing the genome sequence of strain GQJK17 with the other three complete genome sequences of this species, the main gene clusters for producing antimicrobial secondary metabolites were generally similar. Our findings further highlight the evolutionary conservation of $B$. atrophaeus species for biocontrol ability as PGPR.

\section{Data Availability}

The data used to support the findings of this study are available from the corresponding author upon request.

\section{Conflicts of Interest}

All authors declare that they have no conflicts of interest. 


\section{Acknowledgments}

This work was supported by the National Key Research and Development Program of China (no. 2017YFD0200804), the National Natural Science Foundation of China (NSFC, Grants nos. 31700094, 31770115, and 31600090), the Science and Technology Major Projects of Shandong Province (no. 2015ZDXX0502B02), and the funds of Shandong "Double Tops” Program (no. SYL2017XTTD03).

\section{Supplementary Materials}

Supplementary 1. Supplementary S1: the orthogonal test design of B. atrophaeus GQJK17 to optimize the medium.

Supplementary 2. Supplementary S2: the genomic islands information of B. atrophaeus GQJK17 that analyzed by IslandViewer 4.

\section{References}

[1] L.-Y. Wang, Y.-S. Xie, Y.-Y. Cui et al., "Conjunctively screening of biocontrol agents (BCAs) against fusarium root rot and fusarium head blight caused by Fusarium graminearum," Microbiological Research, vol. 177, pp. 34-42, 2015.

[2] Y. Zhao, L. Sangare, Y. Wang et al., "Complete genome sequence of Bacillus subtilis SG6 antagonistic against Fusarium graminearum," Journal of Biotechnology, vol. 194, pp. 10-11, 2015.

[3] K. O’Donnell, T. J. Ward, D. M. Geiser, H. C. Kistler, and T. Aoki, "Genealogical concordance between the mating type locus and seven other nuclear genes supports formal recognition of nine phylogenetically distinct species within the Fusarium graminearum clade," Fungal Genetics and Biology, vol. 41, no. 6, pp. 600-623, 2004.

[4] J. Yang, T. Hsiang, V. Bhadauria, X.-L. Chen, and G. Li, "Plant Fungal Pathogenesis," BioMed Research International, vol. 2017, Article ID 9724283, 2017.

[5] C. E. Windels, "Economic and social impacts of Fusarium head blight: Changing farms and rural communities in the Northern Great Plains," Journal of Phytopathology, vol. 90, no. 1, pp. 17-21, 2000.

[6] D. Tilman, K. G. Cassman, P. A. Matson, R. Naylor, and S. Polasky, "Agricultural sustainability and intensive production practices," Nature, vol. 418, no. 6898, pp. 671-677, 2002.

[7] K. Liu, M. Newman, J. A. McInroy, C.-H. Hu, and J. W. Kloepper, "Selection and assessment of plant growth-promoting rhizobacteria for biological control of multiple plant diseases," Journal of Phytopathology, vol. 107, no. 8, pp. 928-936, 2017.

[8] H. Guo, Y. Yang, K. Liu et al., "Comparative Genomic Analysis of Delftia tsuruhatensis MTQ3 and the Identification of Functional NRPS Genes for Siderophore Production," BioMed Research International, vol. 2016, Article ID 3687619, 2016.

[9] B. Rahmoune, A. Morsli, M. Khelifi-Slaoui et al., "Isolation and characterization of three new PGPR and their effects on the growth of Arabidopsis and Datura plants," Journal of Plant Interactions, vol. 12, no. 1, pp. 1-6, 2017.

[10] S. H. Habib, H. Kausar, and H. M. Saud, "Plant growthpromoting rhizobacteria enhance salinity stress tolerance in okra through ROS-scavenging enzymes," BioMed Research International, vol. 2016, Article ID 6284547, 10 pages, 2016.
[11] S. Sivasakthi, G. Usharani, and P. Saranraj, "Biocontrol potentiality of plant growth promoting bacteria (PGPR)-Pseudomonas fluorescens and Bacillus subtilis: A review," African Journal of Microbiology Research, vol. 9, no. 16, pp. 1265-1277, 2014.

[12] P. P. Reddy, "Plant growth-promoting rhizobacteria (PGPR)," Springer India, vol. 18, no. 3, pp. 131-158, 2012.

[13] P. N. Bhattacharyya and D. K. Jha, "Plant growth-promoting rhizobacteria (PGPR): emergence in agriculture," World Journal of Microbiology and Biotechnology, vol. 28, no. 4, pp. 1327-1350, 2012.

[14] Y. G. Kim, H. K. Kang, K.-D. Kwon, C. H. Seo, H. B. Lee, and Y. Park, "Antagonistic Activities of Novel Peptides from Bacillus amyloliquefaciens PT14 against Fusarium solani and Fusarium oxysporum," Journal of Agricultural and Food Chemistry, vol. 63, no. 48, pp. 10380-10387, 2015.

[15] M. Ongena and P. Jacques, "Bacillus lipopeptides: versatile weapons for plant disease biocontrol," Trends in Microbiology, vol. 16, no. 3, pp. 115-125, 2008.

[16] V. Govindasamy, M. Senthilkumar, V. Magheshwaran et al., "Bacillus and Paenibacillus spp.: Potential PGPR for Sustainable Agriculture," in Plant Growth and Health Promoting Bacteria, vol. 18 of Microbiology Monographs, pp. 333-364, Springer Berlin Heidelberg, Berlin, Heidelberg, 2011.

[17] S. R. B. R. Sella, L. P. S. Vandenberghe, and C. R. Soccol, "Bacillus atrophaeus: Main characteristics and biotechnological applications - A review," Critical Reviews in Biotechnology, vol. 35, no. 4, pp. 533-545, 2015.

[18] T. Stein, S. Düsterhus, A. Stroh, and K.-D. Entian, "Subtilosin Production by Two Bacillus subtilis Subspecies and Variance of the sbo-alb Cluster," Applied and Environmental Microbiology, vol. 70, no. 4, pp. 2349-2353, 2004.

[19] F. Liu, W. Sun, F. Su, K. Zhou, and Z. Li, "Draft genome sequence of the sponge-associated strain Bacillus atrophaeus C89, a potential producer of marine drugs," Journal of Bacteriology, vol. 194, no. 16, pp. 4454-4454, 2012.

[20] L. C. M. Das Neves, K. S. De Oliveira, M. J. Kobayashi, T. C. V. Penna, and A. Converti, "Biosurfactant production by cultivation of Bacillus atrophaeus ATCC 9372 in semidefined glucose/casein-based media," Applied Biochemistry and Biotechnology, vol. 137-140, no. 1-12, pp. 539-554, 2007.

[21] K. Recep, S. Fikrettin, D. Erkol, and E. Cafer, "Biological control of the potato dry rot caused by Fusarium species using PGPR strains," Biological Control, vol. 50, no. 2, pp. 194-198, 2009.

[22] V. Shanmugam, H. Thakur, and S. Gupta, "Use of chitinolytic Bacillus atrophaeus strain S2BC-2 antagonistic to Fusarium spp. for control of rhizome rot of ginger," Annals of Microbiology, vol. 63, no. 3, pp. 989-996, 2013.

[23] H. Huang, Z. Wu, C. Tian, Y. Liang, C. You, and L. Chen, "Identification and characterization of the endophytic bacterium Bacillus atrophaeus XW2, antagonistic towards Colletotrichum gloeosporioides," Annals of Microbiology, vol. 65, no. 3, pp. 13611371, 2015.

[24] X. Zhang, B. Li, Y. Wang et al., "Lipopeptides, a novel protein, and volatile compounds contribute to the antifungal activity of the biocontrol agent Bacillus atrophaeus CAB-1," Applied Microbiology and Biotechnology, vol. 97, no. 21, pp. 9525-9534, 2013.

[25] W. Y. Chan, K. Dietel, S. V. Lapa, L. V. Avdeeva, R. Borriss, and O. N. Reva, "Draft genome sequence of Bacillus atrophaeus UCMB-5137, a plant growth-promoting rhizobacterium," Genome Announcements, vol. 1, no. 3, 2013. 
[26] X.-F. Huang, D. Zhou, J. Guo, D. K. Manter, K. F. Reardon, and J. M. Vivanco, "Bacillus spp: From rainforest soil promote plant growth under limited nitrogen conditions," Journal of Applied Microbiology, vol. 118, no. 3, pp. 672-684, 2015.

[27] H. Amagase and N. R. Farnsworth, "A review of botanical characteristics, phytochemistry, clinical relevance in efficacy and safety of Lycium barbarum fruit (Goji)," Food Research International, vol. 44, no. 7, pp. 1702-1717, 2011.

[28] J.-H. Xie, W. Tang, M.-L. Jin, J.-E. Li, and M.-Y. Xie, "Recent advances in bioactive polysaccharides from Lycium barbarum L., Zizyphus jujuba Mill, Plantago spp., and Morus spp.: Structures and functionalities," Food Hydrocolloids, vol. 60, pp. 148160, 2016.

[29] C. C. Wang, S. C. Chang, B. S. Inbaraj, and B. H. Chen, "Isolation of carotenoids, flavonoids and polysaccharides from Lycium barbarum L. and evaluation of antioxidant activity," Food Chemistry, vol. 120, no. 1, pp. 184-192, 2010.

[30] M. Jin, Q. Huang, K. Zhao, and P. Shang, "Biological activities and potential health benefit effects of polysaccharides isolated from Lycium barbarum L.," International Journal of Biological Macromolecules, vol. 54, no. 1, pp. 16-23, 2013.

[31] Q. Zhang, X. Lv, T. Wu et al., "Composition of Lycium barbarum polysaccharides and their apoptosis-inducing effect on human hepatoma SMMC-7721 cells," Food and Nutrition Research, vol. 59, 2015.

[32] X. M. Li, Y. L. Ma, and X. J. Liu, "Effect of the Lycium barbarum polysaccharides on age-related oxidative stress in aged mice," Journal of Ethnopharmacology, vol. 111, no. 3, pp. 504-511, 2007.

[33] R. Bo, S. Zheng, J. Xing et al., "The immunological activity of Lycium barbarum polysaccharides liposome in vitro and adjuvanticity against PCV2 in vivo," International Journal of Biological Macromolecules, vol. 85, pp. 294-301, 2016.

[34] Z. Lu and G. Wang, "Occurrence and control of wolfberry root rot," Journal of Plant Protection, vol. 21, no. 3, pp. 249-254, 1994.

[35] X.-H. Chen, J. Vater, J. Piel et al., "Structural and functional characterization of three polyketide synthase gene clusters in Bacillus amyloliquefaciens FZB 42," Journal of Bacteriology, vol. 188, no. 11, pp. 4024-4036, 2006.

[36] C.-D. Qian, T.-Z. Liu, S.-L. Zhou et al., "Identification and functional analysis of gene cluster involvement in biosynthesis of the cyclic lipopeptide antibiotic pelgipeptin produced by Paenibacillus elgii," BMC Microbiology, vol. 12, article no. 197, 2012.

[37] K. H. Jang, S.-J. Nam, J. B. Locke et al., "Anthracimycin, a potent anthrax antibiotic from a marine-derived actinomycete," Angewandte Chemie International Edition, vol. 52, no. 30, pp. 7822-7824, 2013.

[38] X. Yang, D. Qiu, H. Yang, Z. Liu, H. Zeng, and J. Yuan, "Antifungal activity of xenocoumacin 1 from Xenorhabdus nematophilus var. pekingensis against Phytophthora infestans," World Journal of Microbiology and Biotechnology, vol. 27, no. 3, pp. 523-528, 2011.

[39] A.-L. Moyne, R. Shelby, T. E. Cleveland, and S. Tuzun, "Bacillomycin D: An iturin with antifungal activity against Aspergillus flavus," Journal of Applied Microbiology, vol. 90, no. 4, pp. 622-629, 2001.

[40] S. M. Eshita and N. H. Roberto, "Bacillomycin Lc, a New Antibiotic of the Iturin Group: Isolations, Structures, and Antifungal Activities of the Congeners," The Journal of Antibiotics, vol. 48, no. 11, pp. 1240-1247, 1995.

[41] M. Kugler, W. Loeffler, C. Rapp, A. Kern, and G. Jung, "Rhizocticin $\mathrm{A}$, an antifungal phosphono-oligopeptide of Bacillus subtilis ATCC 6633: biological properties," Archives of Microbiology, vol. 153, no. 3, pp. 276-281, 1990.

[42] X. H. Chen, A. Koumoutsi, R. Scholz et al., "Comparative analysis of the complete genome sequence of the plant growth-promoting bacterium Bacillus amyloliquefaciens FZB42," Nature Biotechnology, vol. 25, no. 9, pp. 1007-1014, 2007.

[43] Y. E. Sheng-Mei and W. Gao, "Improvement of bacteria's spore staining," Journal of Microbiology, vol. 31, no. 1, pp. 106-109, 2011.

[44] N. Kovacs, "Identification of Pseudomonas pyocyanea by the oxidase reaction," Nature, vol. 178, no. 4535, p. 703, 1956.

[45] W.-J. Li, P. Xu, P. Schumann et al., "Georgenia ruanii sp. nov., a novel actinobacterium isolated from forest soil in Yunnan (China), and emended description of the genus Georgenia," International Journal of Systematic and Evolutionary Microbiology, vol. 57, no. 7, pp. 1424-1428, 2007.

[46] L. Chernin, Z. Ismailov, S. Haran, and I. Chet, "Chitinolytic enterobacter agglomerans antagonistic to fungal plant pathogens," Applied and Environmental Microbiology, vol. 61, no. 5, pp. 1720-1726, 1995.

[47] Q. Shu, J. C. Ding, Q. X. Bao, M. P. Li, and H. Yan, “Orthogonal test design for optimization of the extraction of flavonid from the Fructus Gardeniae," Biomedical and Environmental Sciences, vol. 24, no. 6, pp. 688-696, 2011.

[48] C.-S. Chin, D. H. Alexander, P. Marks et al., "Nonhybrid, finished microbial genome assemblies from long-read SMRT sequencing data," Nature Methods, vol. 10, no. 6, pp. 563-569, 2013.

[49] B. I. Cantarel, P. M. Coutinho, C. Rancurel, T. Bernard, V. Lombard, and B. Henrissat, "The Carbohydrate-Active EnZymes database (CAZy): an expert resource for glycogenomics," Nucleic Acids Research, vol. 37, no. 1, pp. D233-D238, 2009.

[50] M. H. Medema, K. Blin, P. Cimermancic et al., "AntiSMASH: Rapid identification, annotation and analysis of secondary metabolite biosynthesis gene clusters in bacterial and fungal genome sequences," Nucleic Acids Research, vol. 39, no. 2, pp. W339-W344, 2011.

[51] C. Bertelli, M. R. Laird, K. P. Williams et al., "IslandViewer 4: Expanded prediction of genomic islands for larger-scale datasets," Nucleic Acids Research, vol. 45, no. 1, pp. W30-W35, 2017.

[52] M. Krzywinski, J. Schein, I. Birol et al., "Circos: An information aesthetic for comparative genomics," Genome Research, vol. 19, no. 9, pp. 1639-1645, 2009.

[53] J. Zhao, X. Bao, C. Li, Y. Shen, and J. Hou, "Improving monoterpene geraniol production through geranyl diphosphate synthesis regulation in Saccharomyces cerevisiae," Applied Microbiology and Biotechnology, vol. 100, no. 10, pp. 4561-4571, 2016.

[54] L. Chen, "Complete genome sequence of Bacillus velezensis LM2303, a biocontrol strain isolated from the dung of wild yak inhabited Qinghai-Tibet plateau," Journal of Biotechnology, vol. 251, pp. 124-127, 2017.

[55] S. E. Maddocks and P. C. F. Oyston, "Structure and function of the LysR-type transcriptional regulator (LTTR) family proteins," Microbiology, vol. 154, no. 12, pp. 3609-3623, 2008.

[56] M. J. Fritsch, K. Trunk, J. A. Diniz, M. Guo, M. Trost, and S. J. Coulthurst, "Proteomic identification of novel secreted antibacterial toxins of the Serratia marcescens Type VI secretion system," Molecular \& Cellular Proteomics, vol. 12, no. 10, pp. 2735-2749, 2013. 


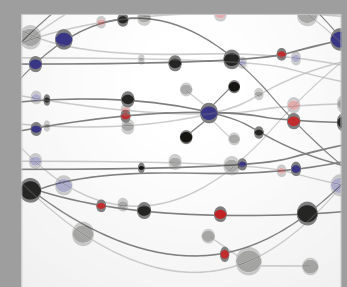

The Scientific World Journal
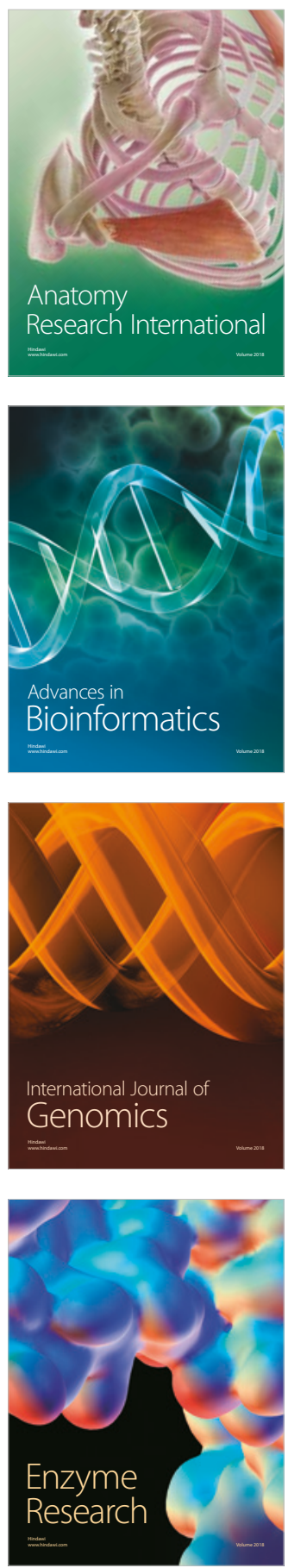
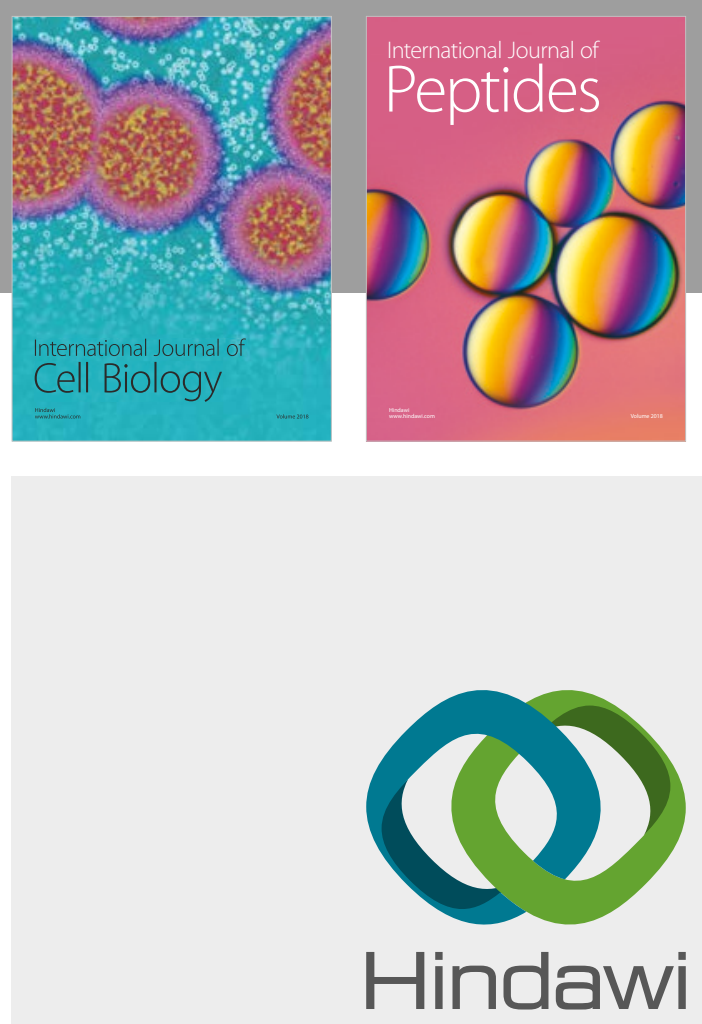

Submit your manuscripts at

www.hindawi.com
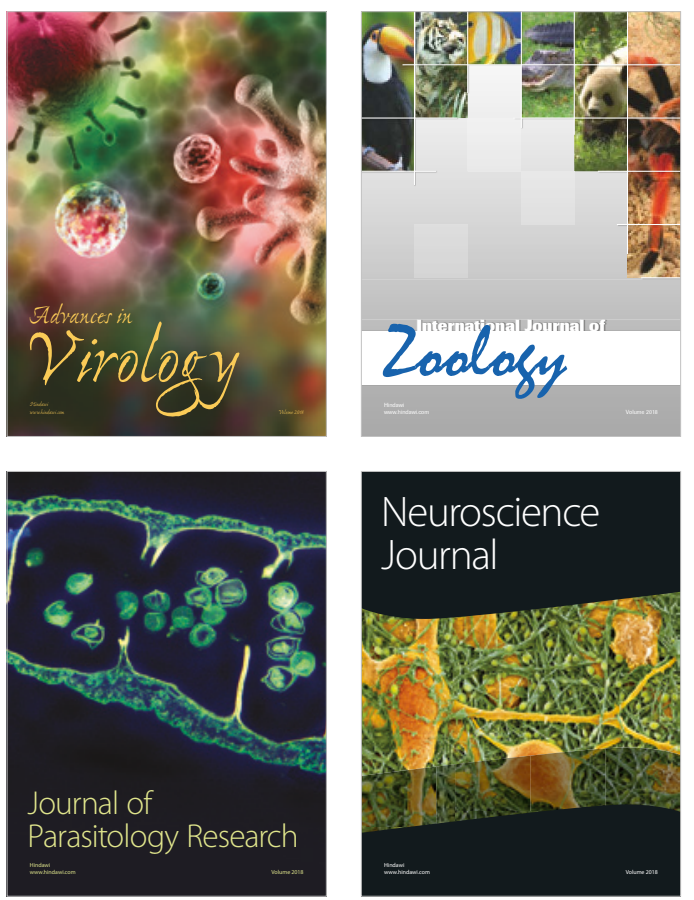
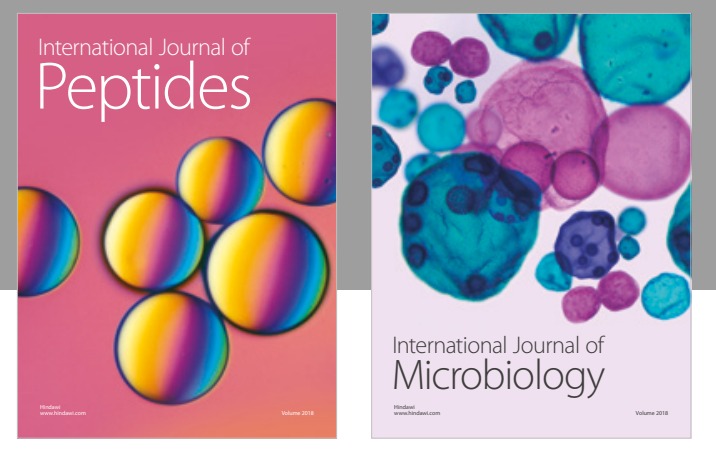

nternational Journal of Microbiology
Journal of
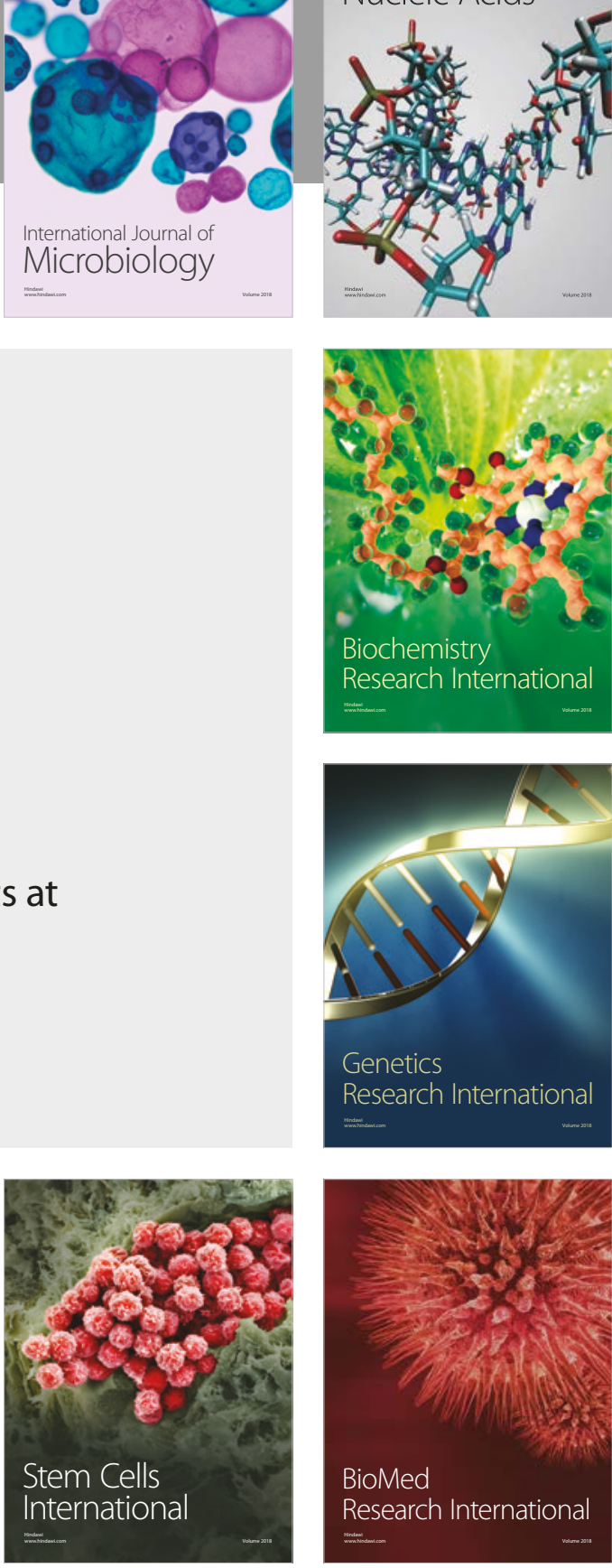
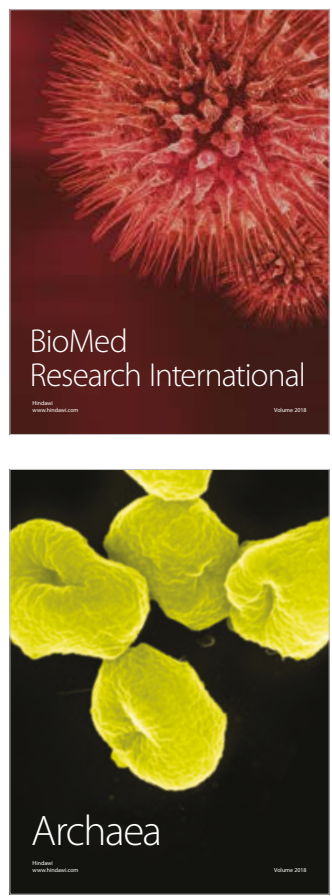